\title{
THE IMPACT OF SERVICE-LEARNING CURRICULUM AT A LOCAL AT-RISK HIGH SCHOOL: AN EXAMINATION OF PRELIMINARY DATA
}

\author{
Roxanne Helm-Stevens, Randy Fall, Cloyd Havens, Michael Garcia and Lacey Polvi \\ School of Business and Management, \\ Azusa Pacific University, 901 E Alosta Ave, Azusa, CA, 91702, USA
}

Received 2014-11-01; Revised 2014-11-07; Accepted 2014-12-04

\begin{abstract}
Over the years, there has been substantial research highlighting the effectiveness of service-learning from the perspective of the student in the classroom. Multiple studies have demonstrated student-learning outcomes as well as provided descriptions of service-learning projects and syllabi. However, limited research has been conducted exploring the effects of service-learning on the community. This pioneering study offers preliminary data on the contribution of service-learning to the community by exploring the relationships between a six-week service-learning project and the community partner. Utilizing STAR test results and principal and student feedback, the researchers examine the outcomes of a six-week college service-learning project at a local urban continuation high school. STAR test results from the California High School Exit Exam from 2008 through 2011 and classroom findings are examined. The results reveal positive changes among the high school student group based upon their evaluative attitudes towards individual strengths, motivation and career choices. Finally, the implications of this study are discussed.
\end{abstract}

Keywords: Service-Learning, Community Benefit, Classroom Design,

\section{INTRODUCTION}

Service-learning, an increasingly prevalent educational model, reflects the union of experiential and academic learning. Howard (1998) suggested that academic service-learning is not possible unless "concerted effort is made to harvest community-based learning and strategically bridge it with academic learning" (p. 34). In comparison to civic responsibility or volunteer activities, service-learning is academic work centered on learning objectives (Domegan and Bringle, 2010). Domegan and Bringle (2010) defined service-learning as a credit-bearing educational course where students participate in organized service activities that meet community needs while reflecting on the service activity in order to gain further understanding of the course material.
Gujarthi and McQuade (2002) noted that developing a working relationship with community organizations where students will be serving is key in ensuring a successful transformative initiative. Ultimately, in the sphere of service-learning curriculum, volunteering has evolved into a two-way transaction between students and community partners.

Boyer (1990) discussed the evolution of American scholarship, from its British-influenced Puritan roots in the colonial era to the current university system. In his analysis, he discussed the shifting focus surrounding the agricultural and mechanical revolutions in the mid1800 s, noted, "Thus, American higher education, once devoted primarily to the intellectual and moral development of students, added service as a mission and both private and public universities took up the challenge" (p. 5).

Corresponding Author:Roxanne Helm-Stevens, School of Business and Management, Azusa Pacific University, 901 E Alosta Ave, Azusa, CA, 91702, USA 
Table 1. Whitcomb high school demographics and suspension rates

\begin{tabular}{|c|c|c|c|c|c|c|c|c|c|c|c|}
\hline \multicolumn{6}{|c|}{ Demographics } & \multicolumn{6}{|c|}{ Suspension rates } \\
\hline \multicolumn{3}{|l|}{ White } & \multicolumn{3}{|c|}{ Hispanic } & \multicolumn{3}{|c|}{ Whitcomb HS } & \multicolumn{3}{|c|}{ GUSD } \\
\hline 08-09 & $09-10$ & $10-11$ & 08-09 & $09-10$ & $10-11$ & 08-09 & 09-10 & $10-11$ & 08-09 & $09-10$ & $10-11$ \\
\hline $50.4 \%$ & $51.4 \%$ & $59.3 \%$ & $27.4 \%$ & $42.3 \%$ & $36 \%$ & 48.7 & 96.6 & 67.4 & 18.6 & 21.4 & 21.4 \\
\hline
\end{tabular}

Boyer also addressed different forms of scholarship, discussing in particular the professoriate's role in the scholarship of application, where the rigor and commitment of research is integrated with practical application, in order to address societal concerns through the utilization of collective knowledge.

As the role of service-learning within higher education continues to adapt with society, it is necessary to assess the impacts of experiential learning on not only the students involved, but also the organizations and individuals being served. As Ward and Wolf-Wendel (2000) noted:

The research literature on the effects of service learning offer an interesting view of what researchers value. The emphasis in this literature is almost exclusively on outcomes (mostly positive) that service learning has on and for students...Although the community stands to benefit from community service, these benefits are not described in the literature (p. 771).

The following study addresses the aforementioned limitation in existing service-learning research by providing a qualitative analysis indicating positive community impact through mentoring relationships between undergraduate students enrolled in a serviceearning course at Azusa Pacific University and a local urban continuation high school.

\subsection{Transformation of the Traditional Classroom}

Over the years, there has been an increased emphasis on giving back to the community. There is a new expectation for schools due to an identified lack of complex problem solving skills in current students who are products of the education system (Casile et al., 2011). With a more modern approach, Leal Filho asserted that successfully educating students to be globally informed and responsible leaders is an indication of the positive outcomes of higher education (as cited in Cress et al., 2010). As a result, this information can be utilized in order to produce healthier communities. In today's modern world, the evolving goal for education is to produce critically, civically and globally minded individuals who are experienced in problem solving and leadership roles (Cress et al., 2010). Buys and Bursnall (2007) have suggested that in such a rapidly changing society, it is imperative that communities and universities become more connected in order to build sustainable relationships and ultimately strengthen social capital.

\section{LITERATURE REVIEW}

\subsection{Service-Learning in Higher Education}

Implementing service-learning projects within business courses at the university-level is proven to have positive effects on both the community and the students involved. In numerous instances, studies on the effects of service-learning projects demonstrated marginal growth for the community partner. In one particular study, nearly three-fourths of students reported having a greater sense of responsibility as well as a more defined leadership role while making a positive difference in the community (Cress et al., 2010). A study by Joseph et al. (2007) identified that community participation among business students is higher than that of non-business students. For example, West and Simmons (2012) interviewed Catherine, a 22-year-old business student who shared her evaluative thoughts on the servicelearning project in which she was involved:

"I enjoyed applying PR and marketing to a new field I didn't realize could make use of the concepts. As a business student, most classes seem to always focus on how to increase profits. I finally realized that maybe what we are learning is actually applied to the real world. This project was far better than a simulation or case study. Simulation and cases are okay, but more abstract. I will likely use the problem-solving techniques I learned to apply and I feel like I have a better grasp of the concepts. I will remember all of this stuff 
much longer than if I'd just done some virtual project or read about something (p. 129).

Casile et al. (2011) identified that within a group of 90 accounting students, the majority indicated more satisfaction with the course due to service-learning integration. Not only that, but they also felt that they had developed better interpersonal and critical thinking skills.

In addition to the transformational effects of servicelearning on a student's academic growth, there are also great benefits for the organization. For example, Tucker et al. (1998) and colleagues identified that students in entrepreneurship or strategy classes can make a positive impact on a community organization by using their knowledge to develop business plans for projects to benefit low-income communities. As identified by Ayers et al. (2010), this form of community engagement improves a student's professional toolbox as well as provides an opportunity to interact in team settings.

Service-learning has been shown, to some degree, to provide benefits for the following participants: the educational institution, the individuals serving, the individuals being served and the organizations being served (Bringle and Hatcher, 1996). Many studies have addressed the impact on the student and the educational institution, but fewer have focused on the benefits for the individuals and the organizations being served.

\subsection{Educational Institution}

Prior studies have identified many benefits for the educational institution, including positive perceptions of the university by the community (Miron and Moely, 2006), enhanced student retention rates (Eyler et al., 2001), positive teaching and learning outcomes such as greater student involvement and participation in class (Caruso et al., 2006) and increased opportunities for meaningful research and scholarly activities (Strand et al., 2003). Seifer (1998) suggested that service-learning has become a response to higher education trends, including the demand for greater accountability for publicly-funded institutions and discussions of whether undergraduate curriculum successfully develops critical thinkers and engaged citizens.

\subsection{Individuals Serving}

In this study and related research the individuals serving are university students who are collaborating with the community partner. The studied benefits to individuals serving include cultural awareness sharing (Crabtree, 2008), as well as networking opportunities and application of classroom learning to real-world issues (Bowen et al., 2009). Ultimately, service-learning stimulates student learning and engages students in their surrounding communities. These types of projects allow students to utilize material learned in the classroom to improve the conditions of society. Service-learning creates new goals for students such as personal development, career development, moral development, academic achievement and "reflective civic participation" (Lamb et al., 1998). As Tucker et al. (1998) noted, knowledge is the process created through transformative experiences and research shows that service-learning projects can be transformative for both individuals serving and those being served.

Overall, Buys and Bursnall (2007) concisely identified some of the more prominent benefits attained by students and community members, including:

(a) New insights and learning; (b) better informed community practice; (c) career enhancement for individuals involved with the partnership; (d) improvement in the quality of teaching and learning; (e) increased opportunity for student employment; (f) additional funding and access to information; (g) more frequent and higher-quality publications; and (h) more rapid speed of internationalization. (p. 74)

By integrating concepts and theories learned in the classroom with everyday life, students are more capable of highlighting the importance of each course. Additionally, material learned in business courses can be applied to benefit the community through a variety of tangible services, such as business planning or marketing new programs. Service-learning is an excellent way for students to apply their course lessons to real-world situations and concurrently benefit the community.

Morin (2009) noted that service-learning provides realism outside of the classroom for students. Servicelearning initiatives not only aid students academically, but also produce more externally-focused individuals dedicated to improving their community.

\subsection{Individuals and Organizations being Served}

A limited number of articles have examined the positive impacts of service-learning on the community. Existing studies have focused on qualitative data, with preliminary data formed from observation. For the purposes of this study, individuals and organizations being served refer to the community partner. 
Benefits to individuals discussed in previous research include the positive effects of age-appropriate role models (Sandy and Holland, 2006), as well as increased test scores and improvement on outlook and academic goals (Schmidt and Robby, 2002). In their comprehensive study, Miron and Moely (2006) discuss three contributions to the corpus of research exploring community benefit. The first is a study by Vernon and Ward (1999) surveying 65 community members involved with service-learning projects at four colleges or universities. They found that $92 \%$ of respondents held a positive view of the institutions and $87 \%$ "agreed" or "strongly agreed" that other members in the community also perceived the colleges or universities positively. The second study was Ferrari and Worrall's (2000) survey of 30 communitybased organization supervisors who expressed very positive perceptions of the university students with whom they were working. One notable limitation of that study was the potential bias of supervisors concerned with jeopardizing their relationships with the university, necessitating a discussion of motivation when analyzing the impact of projects that rely on participant feedback. The third study was Schmidt and Robby's (2002) examination of children being served through a university service-learning tutoring program, which was created through collaboration between the university and school district. The authors suggested that the broad participation between university faculty and school administration positively influenced the program design and implementation.

Another significant contribution was a study by Carter and Spotanski (1989) that observed the personal and leadership life skills development of high school students who served as officers in student or community organizations. Phelps and Kotrlik (2007) also considered life skills development through their study of high school students participating in 4-H activities. The results did not provide conclusive evidence indicating correlation, but the study revealed relationships between involvement in the organization and the development of certain skills, which also increased with age and years of involvement (Phelps and Kotrlik, 2007).

Miron and Moely (2006) conducted a survey of supervisors from 40 community agencies engaged in a university-based service-learning program. They employed a quantitative measure to identify four agency characteristics: agency voice, interpersonal relations, agency benefit and perception of university. They found that participants who were involved in the program planning and implementation, as well as those who perceived positive relationships between the community members and students benefited most from the service-learning experience.

Additionally, organizations could benefit from an increased workforce due to the exposure of volunteers to the cause as well as more opportunity to recruit temporary volunteers for extended service (Blouin and Perry, 2009). Other benefits are increased access to university resources and an increased enthusiasm from younger workers (Cruz and Giles, Jr., 2000), the greater reliability of service-learners as compared to volunteers (Bush-Bacelis, 1998) and the creation of ongoing partnerships with the institution (Lamberty, 2012).

\subsection{Building the Partnership}

Prior research has also indicated best practices for creating and maintaining a partnership between the educational institution and the organization. Suggested strategies include building relationships, joint involvement in the determination of goals and methods, fair exchange of resources, preparation of students prior to service and institutional commitment and consistency (Jacoby, 1996).

Cruz and Giles, Jr. (2000) proposed a four-part model to assess the process and outcomes of community service, acknowledging that existing programs may approximate this model. The goal of the model is to improve research for the purpose of refining servicelearning practice. The four parts are:

- The partnership as the unit of analysis. This is the question of whether the partnership between the university and the organization is better as a result of service-learning

- Consistency with good service-learning practice principles. A good service-learning program should follow the principles of good practice in both the service and the evaluation and research. These principles include community input, reciprocity and partnership

- Use of action research. To provide the most valid data while avoiding harm to community relationships, there should be a commitment to meeting community needs, partnership with the community in defining and stating the goals and a moral commitment to transform injustice in the community

- Focus on assets. The project should focus on improving the assets of the community, rather than attempting to remedy a deficit 
The present study addresses the second, third and fourth parts of the model. The program being studied strictly followed good practices by involving the community partner in the design and implementation of the program, in order to address community needs. The sole focus of the program is the students, which are the primary asset of the community. Future studies could be designed to measure the impact of service on the partnership between the university and the community.

\section{BACKGROUND OF AZUSA PACIFIC UNIVERSITY SERVICE-LEARNING PROGRAM}

\subsection{University Service-Learning Program Participants}

The undergraduate students participating in the service-learning program were juniors and seniors at Azusa Pacific University, a medium-sized private Christian university in Southern California. The program represented an integrated service-learning component for an Organizational and Administrative Behavior class, a required course for Business majors and minors. Students were placed into peer groups and assigned to classrooms in various participating high schools, where they remained for six weeks following one week of orientation. Many of the activities and exercises in the service-learning program curriculum were designed to facilitate mentoring conversations over time. This ensured that relationship building and role modeling were integrated throughout the project. Students rotated job responsibilities each week, allowing them to experience different roles and develop deeper understanding of their strengths and weaknesses. Although guidance was available upon request, the students maintained primary responsibility for delivering the curriculum, working together each week to create new strategies. Following each lesson, the groups would engage in performance self-evaluation and each member would evaluate the overall group performance and then provide individual constructive criticism.

\subsection{Description of Service-Learning Program}

The Options: Business Education and Life Skills for Urban Youth program (Options) was developed in 2009 as a community-service learning project for Azusa Pacific University undergraduate students enrolled in courses through the APU School of Business and Management. Designed to serve the local community, the program facilitated mentoring relationships between APU students and underserved, at-risk high school students through six-week teaching assignments where the university students delivered modules on topics encompassing career and personal skills development. The program was built around two core pillars: education and mentoring and its holistic approach supports high school students by providing opportunities for relationship building and role modeling. Options was specifically designed to meet the needs of alternative high school students within the community and the curriculum and mentorship opportunities provide participating students with the skills necessary to succeed academically and contribute to society. The Options program contributed to the personal and academic growth of participating high school students through relevant curriculum designed to engage and equip students. The module topics included lessons titled Study Skills, Goal Setting and Why Self-Esteem and Self-Knowledge Matter, as well as material preparing students for post-high school, such as how to write a resume or conduct a job search. The following exploratory study suggests that the improved academic proficiency indicated through the California STAR test results following the Options program can be partially attributed to the high school students' interaction with university students and the development of a positive mentoring relationship.

\section{METHOD}

\subsection{Research Question}

The purpose of this study was to determine the impact of service-learning on high school students in a local urban continuation high school. This study sought to identify whether the high school student group experienced positive changes in their evaluative attitudes of individual strengths, motivation and career choices. Before analyzing the data received in regard to this question, we will describe the student population surveyed in the study.

\subsection{Demographic of Individuals being Served}

Whitcomb High School is a California Model Continuation High School that provides opportunities for students with an emphasis on attendance, participation and class work. The Whitcomb High School mission states, "At Whitcomb High School, we believe that all students are capable of reaching their own unique potential. Therefore, we offer a challenging, standards- 
based curriculum within a safe, caring and personalized environment, that will enable students to meet their educational and life goals" (Whitcomb High School: A California Model Continuation School, 2014).

The Glendora Unified School District is comprised of two high schools, Glendora High School and Whitcomb High School. Whitcomb offers a credit recovery program in an alternative setting by serving students ages 16 and older with a variety of needs, including those not on track to graduate, employed students and those who need more individualized curriculum and instruction. The continuing education program also serves students who have been transferred from Glendora High School due to poor attendance or inappropriate behavior (Whitcomb High School: A California Model Continuation School, 2014).

The School Accountability Report Cards from the academic years of 2008-2011 indicate that the student population of Whitcomb High School was primarily White and Hispanic, with minimal representation from other ethnicities. In order to gain a better understanding of the context of Whitcomb High School, suspension rates were compared to the Glendora Unified School District (GUSD). For the years of 2008-2011, Whitcomb displayed a significantly higher suspension rate than the overall school district, which can be seen in detail below. Table 1 shows the percentages of White and Hispanic students as well as compares the suspension rates for Whitcomb High School and the Glendora Unified School District (GUSD).

According to the California Department of Education, 10 out of 45 total Grade 12 graduates in 2008-2009 were socioeconomically disadvantaged. In 2009-2010, 9 out of 38 Whitcomb graduates were socioeconomically disadvantaged and in 2010-2011, 3 out of 48 were socioeconomically disadvantaged (CDE, 2014). The socioeconomic status of the general student ggpulation of Whitcomb can be partially attributed to the geographic location, as the school serves surrounding trailer parks.

\subsection{Measures}

Data to measure the effectiveness of the Options curriculum included qualitative reflections from the high school students at the end of week 3 and week 6, qualitative reflection from the high school principle and quantitative data collected from the California STAR results and California High School Exit Exam.

\section{RESULTS}

The Whitcomb High School students connected with their mentors primarily due to closeness in age. The university students are 'big sisters and brothers' who have successfully navigated high school and progressed into the next stage of life-college and career.

Following the program, students displayed increased positive morale regarding their future, despite their circumstances and they had a better understanding of their career options and the actions required to accomplish their goals. Detailed below are two examples of positive student responses as well as one example of school administrator feedback regarding the Options program during Spring 2012 which illustrate the positive impact of the mentoring relationship facilitated by the program.

\section{Example 1:}

\section{Week 1 Exercise, "What do you want to do when you grow up?"}

When asked, "What do you want to do when you grow up?" over the course of the first two weeks, the students either did not provide an answer or responded with basic jobs. Examples of answers in week one and two were "sales clerk," "I don't want to be anything," "don't want to work," "mother," or "cosmetology." Over half of the students didn't provide any answer.

\section{Week 5 Exercise, "What do you want to do when you grow up?"}

In the fifth week of the program, the students were again asked, "What do you want to do when you grow up?" The majority answered with high-level jobs. Examples of average answers from week five: "marine," "doctor," "pediatrician," businesswoman," and "child physiologist." When asked "Why?" the students responded with positive and self-encouraging responses.

\section{Example 2:}

\section{Week 2 Exercise, "What are your strengths?"}

In the second week of the program, the students were asked, "What are your strengths?" Most student answers were vague, insincere, or negative. Examples of answers included: "Don't know," "nothing," "I don't have any strength," "good fighter," "dancing," and "I talk a lot."

\section{Week 6 Exercise, "What are your strengths?"}


Table 2. STAR test scores, percentage of students scoring proficient or advanced: Whitcomb high school Vs. District Vs. State

\begin{tabular}{|c|c|c|c|c|c|c|c|c|c|}
\hline \multirow[b]{2}{*}{ Subject } & \multicolumn{3}{|c|}{ Whitcomb } & \multicolumn{3}{|c|}{ District } & \multicolumn{3}{|l|}{ State } \\
\hline & 08-09 & $09-10$ & $10-11$ & 08-09 & $09-10$ & $10-11$ & 08-09 & $09-10$ & $10-11$ \\
\hline English Language Arts & $8 \%$ & $19 \%$ & $21 \%$ & $70 \%$ & $69 \%$ & $71 \%$ & $49 \%$ & $52 \%$ & $54 \%$ \\
\hline Mathematics & $1 \%$ & $3 \%$ & $8 \%$ & $65 \%$ & $65 \%$ & $66 \%$ & $46 \%$ & $48 \%$ & $50 \%$ \\
\hline Science & $5 \%$ & $16 \%$ & $21 \%$ & $71 \%$ & $72 \%$ & $76 \%$ & $50 \%$ & $54 \%$ & $57 \%$ \\
\hline History/Social Science & $3 \%$ & $6 \%$ & $21 \%$ & $61 \%$ & $61 \%$ & $65 \%$ & $41 \%$ & $44 \%$ & $48 \%$ \\
\hline
\end{tabular}

Table 3. California high school exit exam, percent passing

\begin{tabular}{|c|c|c|c|c|c|c|c|c|c|}
\hline \multirow[b]{2}{*}{ Subject } & \multicolumn{3}{|c|}{ Whitcomb } & \multicolumn{3}{|c|}{ District } & \multicolumn{3}{|l|}{ State } \\
\hline & 08-09 & $09-10$ & $10-11$ & 08-09 & 09-10 & $10-11$ & 08-09 & $09-10$ & $10-11$ \\
\hline English & $44 \%$ & $62 \%$ & $92 \%$ & $91 \%$ & $91 \%$ & $91 \%$ & $79 \%$ & $81 \%$ & $81 \%$ \\
\hline Mathematics & $61 \%$ & $61 \%$ & $36 \%$ & $92 \%$ & $92 \%$ & $92 \%$ & $80 \%$ & $81 \%$ & $81 \%$ \\
\hline
\end{tabular}

When asked the same question again in the sixth week, student answers were more detailed, positive and sincere. Examples of average answers in week six: "Friendly," “caring," "good listener," "optimistic," "smart," "warm hearted," and "I have dignity."

The above examples illustrate the change in perspective many Whitcomb students experienced as a result of the six-week Options program. The development of answers indicate increased positive outlook regarding individual strengths and skills as well as future career goals.

\section{Example 3:}

\section{Administrator Feedback:}

The quote below, dated April 2012, is from the Whitcomb High School principle and describes the value of mentoring and role-modeling for participating high school students:

I personally place a very high value on this partnership and I do believe that it is mutually beneficial. One of the most important elements of the program for our students is that they are exposed to the role model of the college student. These are peers just a few years older than they, but they are seldom if ever exposed to young men and women who have had practice at setting and achieving goals in their lives. The professional dress is very important to me as well, as it is something my students rarely see in young men and women. My students benefit if someone even asks them to try to envision a future for themselves. They benefit from thinking about possible career paths and how to get there from here. But mostly, they benefit from someone taking the time to come into their world and talk to them.

I know that my students are NOT easy. They are mouthy and often defiant. They struggle when asked to envision a future. They do not have good models at home and are often unsupervised for most of their day outside of school. They use and abuse controlled substances and sexual activity. I believe that this is a valuable exposure for the college students and that it will stretch and widen them as Christian individuals headed into a diverse world. The journey includes trying to establish relationships of trust with the continuation high school students before they can ever hope to teach them anything. Therefore, even though the curriculum is good and valuable in and of itself, it is not the primary reason that I believe in this program. The interpersonal learning is the primary reason.

In addition to the above examples, this study also analyzed California STAR and Exit Exam results for the relevant years in order to assess the academic impact of participation in the Options program.

\subsection{California STAR Results}

While no claims can be made about causation, the Options curriculum was concurrent with substantial test score gains among students at Whitcomb.

The California STAR test results in Table 2 show remarkable progress for students at Whitcomb. From 2008 to 2011, the percentage of students meeting or 
exceeding the California state standards (proficient or advanced) in English/Language Arts rose from 8\% to $21 \%$. The percentage scoring proficient or advanced in Mathematics rose from $1 \%$ to $8 \%$. In Science, the percent scoring proficient or advanced rose from $5 \%$ to $21 \%$. The largest increase was seen in History/Social Studies, with improvement from $3 \%$ to $21 \%$ scoring proficient or advanced. These gains occurred over a period when the comparable district and state scores showed gains in the range of $1 \%$ to $5 \%$.

\subsection{California High School Exit Exam}

Results of the California High School Exit Exam (Table 3) show a remarkable gain in English, but a drop in Mathematics. It is important to remember that Whitcomb is a small continuation high school and CAHSEE results are based on test results from 10th grade students. Whitcomb had between 7 and 20 10th grade students from 2008-2011, meaning that the CAHSEE results could change dramatically based on the performance of a few students. From 2008 to 2011, the percentage of Whitcomb students scoring proficient in the English portion of the exam rose from $44 \%$ to $92 \%$. The percentage scoring proficient on the Mathematics test dropped from $61 \%$ to $36 \%$.

\subsection{Limitations}

As with many qualitative and quantitative studies, there exist some limitations. The first limitation is the methodology. Due to the qualitative nature of this study, it was difficult to achieve causal inferences from the data.

The second limitation is the context of this study. Because it was conducted in a single continuation education high school, Whitcomb High School, the findings may be colored by the cultural and situational factors related to the geographic and socioeconomic location. As a result, caution needs to be exercised in interpreting results in other settings.

The third limitation is the method of data collection that was hindered due to the difficulty of collecting the questionnaires. Due to the nature of Whitcomb High School, many students transfer temporarily from Glendora High School; as a result some students did not participate in Options for the full six weeks and it was difficult to measure student responses.

The final limitation reflects the difficulty of gathering data as a result of the restricted sample size. The research presented could benefit from a focused examination and analysis of individual student data, but it is difficult to access information because there are not many continuing education high schools in Southern California and the data gathering and reporting in these schools is not consistent. An additional factor contributing to the sample size limitation is that there does not exist a single source providing data for the continuing education high schools. Chiang (2008) noted the difficulties with obtaining field data for service-learning projects and identified the amount of labor involved in gathering data as an obstacle. Furthermore, because the support and involvement required by the community partner is crucial in the beginning and throughout the assignment, much of faculty's time is spent preparing for and managing the service-learning assignment with little time left for measuring community benefit. Moreover, the data is often incomplete and time consuming to gather.

These limitations necessitate that researchers find empirically sound alternative methods to investigate and examine the effectiveness of and benefits from servicelearning to communities. Hence, notwithstanding the limitations of this research, we present a thorough study complete with the richness of available data. It is our goal to add to the early body of knowledge on this increasingly important topic.

\section{DISCUSSION}

In alignment with existing research, it was observed that the Options program has demonstrated the desired educational outcome for participating Azusa Pacific University college students. They learned teamwork (Helm-Stevens and Griego, 2009b), organizational skills and confidence (Stevens et al., 2009), leadership and an awareness of themselves and the surrounding community's needs (Helm-Stevens and Griego 2009a; Park et al., 2009). Additionally, this study contributed to the existing body of research regarding community benefit by indicating positive impact for the participating high school students based on the qualitative analysis of their questionnaire responses and the quantitative results of the California STAR and California High School Exit Exam. The participating Whitcomb students have shown an overall increase in grades, test scores, participation and outlook. The continuing relationship between the two groups (the university and high school students) has also been an encouraging indication of the validity and sustainability of this model.

A number of the college students continued to mentor the high school students after the program was complete, which is consistent with the findings in Blouin and Perry (2009) regarding the ongoing benefit to the organization of having experienced workers beyond the scope of the 
program. Finally, the benefits to high school students are consistent with the objectives of the school and the district and are a benefit to the community at large.

The Options model was beneficial because of its highly interactive nature and relevance. The interactive exercises and discussions that comprised the module curriculum were tailored specifically to the students in order to engage them with the material. Beyond the curriculum, the program's main benefit to the participants was the connection provided by APU students as role models and mentors.

\subsection{Recommendations}

This study indicates a significant, positive outcome for the community. Notwithstanding the limitations inherent in the study, the program should continue to be developed in partnership with the community.

Because of the limitations of this study, more research should be conducted to test the perceived results. The ongoing challenge is to obtain relevant data and collection methods, while not impeding the program, or its apparent success. Future studies could address the following limitations:

- Cause and effect-It would be difficult to design a study allowing for a causal relationship to be proven, due to the problems associated with having a control group in this setting. A description of the process and the results over a larger and more diverse sample may be the best model in this circumstance

- The sample size-By expanding this program into multiple schools of varying size and demographic composition, the results would be more reliable. The program, or a similar program, could be introduced in a traditional high school, to determine effectiveness for a different student population. The program could also be instituted as a community program, not directly related to a school setting

- Data collection-Due to reliance on participant feedback, data was difficult to obtain in a timely manner. A subsequent study may utilize data that can be more reliably collected, or have a mechanism that would allow for immediate collection

\section{CONCLUSION}

The above research raises important questions about how to most effectively measure community benefit of service-learning as well as identifies existing limitations in current research. The beneficial impact of service on the community has been demonstrated in the context of this study through the qualitative analysis of student responses and California STAR and California High School Exit Exam results. The benefits include an overall increase in grades and test scores for participating students and an improved outlook on future personal and academic success, improvements which were achieved with only six one-hour interactions through the duration of the Options program. If these results can be confirmed, they will indicate a high degree of effectiveness for this type of program in similar communities. It would be pertinent to conduct further research on community benefits addressing the limitations described above. Addressing the reciprocal benefits of service-learning is essential for effective integration of service-learning into higher education curriculum and the scope of this study provides an essential perspective on opportunities for further study of this topic.

\section{FUNDING INFORMATION}

No external funding was provided for this study.

\subsection{Author's Contributions}

Roxanne Helm-Stevens: Conducted the review of literature and qualitative research and contributed to the writing of the publication.

Randy Fall: Gathered and analyzed secondary empirical data, primarily consisting of school statistics.

Cloyd Havens: Conducted the review of literature and qualitative research and contributed to the writing of the publication.

Michael Garcia: Gathered and analyzed primary data, primarily field research from Whitcomb School.

Lacey Polvi: Conducted the review of literature and qualitative research and contributed to the writing of the publication.

\subsection{Ethics}

The authors do not anticipate any potential ethical issues that could arise as a result of the publication of this manuscript.

\section{REFERENCES}

Ayers, L., T.L. Gartin, B.D. Lahoda, S.R. Veyon and M. Rushford et al., 2010. Service learning: Bringing the business classroom to life. Am. J. Bus. Educ., 3: 55-60.

Blouin, D.D. and E.M. Perry, 2009. Whom does service learning really serve? Community-based organizations' perspectives on service learning. Teaching Sociol., 37: 120-135. DOI: 10.1177/0092055X0903700201 
Bowen, G.A., D.D. Burke, B.L. Little and P.H. Jacques, 2009. A comparison of service-learning and employee volunteering programs. Academy Educ. Leadership J., 13: 1-16.

Boyer, E.L., 1990. Scholarship Reconsidered: Priorities of the Professoriate. Carnegie Foundation for the Advancement of Teaching, Princeton, N.J., ISBN10: 0787940690 , pp: 147.

Bringle, R.G. and J.A. Hatcher, 1996. Implementing service learning in higher education. J. Higher Educ., 67: 221-239. DOI: 10.2307/2943981

Bush-Bacelis, J.L., 1998. Innovative pedagogy: Academic service-learning for business communication. Bus. Communi. Q., 61: 20-34. DOI: $10.1177 / 108056999806100303$

Buys, N., and S. Bursnall, 2007. Establishing universitycommunity partnerships: Processes and benefits. J. Higher Education Policy Manage., 29: 73-86. 10.1080/13600800601175797

Carter, R.I. and D.R. Spotanski, 1989. Perceptions of leadership and personal development of selected high school students in Iowa. J. Agric. Educ., 30: 30-34. DOI: 10.5032/jae.1989.04030

Caruso, R., G. Bowen and J. Adams-Dunford, 2006. Student affairs and service learning: Promoting student engagement. College Student Affairs J., 25: 186-198.

Casile, M., K. Hoover and D. O'Neil, 2011. Both-and, not either-or: Knowledge and service-learning. Educ. Training, 53: 129-139.

CDE, 2014. Graduates by Ethnicity for 2008-2009. California Department of Education Educational Demographics Unit.

Chiang, B., 2008. Integrating a service-learning project into management accounting coursework-a sharing of implementation experience and lessons learned. Accounting Educ. Int. J., 17: 431-445. DOI: 10.1080/09639280802436657

Crabtree, R.D., 2008. Theoretical foundations for international service-learning. Michigan J. Community Service Learning, 15: 18-36.

Cress, C.M., M. Yamashita, R. Duarte and H. Burns, 2010. A transnational comparison of service-learning as a tool for leadership development. Int. J. Organizational Analysis, 18: 228-244. DOI: $10.1108 / 19348831011046281$

Cruz, N.I. and D.E. Giles, Jr., 2000. Where's the community in service-learning research? Michigan J. Community Service Learning, 7: 28-34.
Domegan, C. and R.G. Bringle, 2010. Charting social marketing's implications for service-learning. J. Nonprofit Public Sector Marketing, 22: 198-215. DOI: $10.1080 / 10495142.2010 .483272$

Eyler, J., D. Giles and C.J. Gray, 2001. At a Glance: What We Know about the Effects of Servicelearning on Students, Faculty, Institutions and Communities, 1993-1999. 1st Edn., Washington, DC: Learn and Serve America/National Service Learning Clearinghouse. pp: 45.

Ferrari, J.R. and L. Worrall, 2000. Assessments by community agencies: How "the Other Side" sees service-learning. Michigan J. Community Service Learning, 7: 35-40.

Gujarthi, M.R. and R.J. McQuade, 2002. Servicelearning in business schools: A case study in an intermediate accounting course. J. Educ. Bus., 77: 144-150. DOI: 10.1080/08832320209599063

Helm-Stevens, R. and O. Griego, 2009a. Measuring group experience within the framework of an undergraduate business community service assignment. Int. J. Global Bus. Economics, 2: 129-131.

Helm-Stevens, R. and O. Griego, 2009b. Evaluating experiential learning in organizational behavior: Taking measure of student perception regarding group experience. Am. J. Econ. Bus. Admin., 1: 138-149. DOI: 10.3844/ajebasp.2009.138.140

Howard, J.P.F., 1998. Academic Service Learning: A Counternormative Pedagogy. In: Academic Service Learning: Pedagogy of Action and Reflection, Rhoads, R.A. and J.P.F. Howard (Eds.). New Directions for Teaching and Learning. San Francisco: Jossey-Bass, pp: 21-29.

Jacoby, B., 1996. Service Learning in Higher Education: 3-25. San Francisco: Jossey Blass.

Joseph, M., G.W. Stone, K. Grantham, N. Harmancioglu and E. Ibrahim, 2007. An exploratory study on the value of service learning projects and their impact on community service involvement and critical thinking. Quality Assurance Educ., 15: 318-333. DOI: $10.1108 / 09684880710773192$

Lamb, C.H., R.L. Swinth, K.L. Vinton and J.B. Lee, 1998. Integrating service learning into a business school curriculum. J. Management Educ., 22: $637-$ 654. DOI: $10.1177 / 105256299802200506$

Lamberty, K.M., 2012. Toward a spirituality of accompaniment in solidarity partnerships. Missiology: An Int. Rev., 40: 181-193. 
Miron, D. and B.E. Moely, 2006. Community agency voice and benefit in service-learning. Michigan $\mathrm{J}$. Community Service Learning, 12: 27-37.

Morin, E.L., 2009. Service learning pitfalls: Problems you didn't see coming. College Teaching Methods Styles J., 5: 43-52.

Park, D., R. Helm, D. Kipley and D. Hancock, 2009. Connecting faith and personal values with the service-learning experience to create more effective service learning. Bus. Renaissance Q., 4: 61-76.

Phelps, C.S. and J.W. Kotrlik, 2007. The relationship between participation in community service-learning projects and personal and leadership life skills development in 4-H leadership activities. J. Agric. Educ., 48: 67-81. DOI: 10.5032/jae.2007.04067

Sandy, M. and B.A. Holland, 2006. Different worlds and common ground: Community partner perspectives on campus-community partnerships. Michigan J. Community Service Learning, 13: 30-43.

Schmidt, A. and M.A. Robby, 2002. What's the value of service-learning to the community? Michigan J. Community Service Learning 9: 27-33.

Seifer, S.D., 1998. Service-learning: communitycampus partnerships for health professions education. Academic Medicine, 73: 273-277.

Stevens, R., O. Griego and C. Faber, 2009. Service learning: Undergraduate student perceptions in confidence and skill and personal ability in a business service-learning experience. J. Bus. Behavioral Sci., 20: 122-132.
Strand, K., N. Cutforth, R. Stoecker, S. Marullo and P. Donohue, 2003. Community-based research and higher education: Principles and practices. San Francisco: Jossey Blass.

Tucker, M., A. McCarthy, J. Hoxmeier and M. Lenk, 1998. Community service learning increases communication skills across the business curriculum. Bus. Communication Q., 61: 88-99. DOI: $10.1177 / 108056999806100211$

Vernon, A. and K. Ward, 1999. Campus and community partnerships: Assessing impacts and strengthening connections. Michigan J. Community Service Learning, 6: 30-37.

Ward, K. and L. Wolf-Wendel, 2000. Community-centered service learning: Moving from doing for to doing with. American Behavioral Scientist, 43: 767-781.

West, J. and D. Simmons, 2012. Preparing Hispanic students for the real world: Benefits of problembased service learning projects. J. Hispanic Higher Educ., 11: 123-135. DOI: 10.1177/1538192712437037

Whitcomb High School: A California Model Continuation School, 2014. 